\title{
Genetic structure of the common sole (Solea solea) in the Bay of Biscay: Nurseries as units of selection?
}

\author{
B. Guinand ${ }^{a, c,}{ }^{*}$, J.L. Rolland ${ }^{b}$, F. Bonhomme $e^{a, c}$
}

\begin{abstract}
a Université Montpellier II, Institut des Sciences de I'Evolution de Montpellier, Biologie Intégrative, UMR CNRS 5554, Place Eugène Bataillon - cc63, 34095 Montpellier Cedex 5, France

${ }^{\mathrm{b}}$ Université Montpellier II, IFREMER, Réponse Immunitaire, Aquaculture, Environnement, Place Eugène Bataillon - cc63, 34095 Montpellier Cedex 5, France

${ }^{c}$ Station Méditerranéenne de l'Environnement Littoral, 1 Quai de la Daurade, 34200 Sète, France
\end{abstract}

*: Corresponding author : Guinand B., Tel . (+33) 4671446 87, Fax. (+33) 4671445 54, email address : guinand@univ-montp2.fr

\begin{abstract}
:
Coastal and estuarine areas in the Bay of Biscay are essential nursery habitats for sole (Solea solea). Using three intronic markers, we investigated patterns of genetic differentiation among cohorts of juveniles $(0+, 1+$, sub-adults) inhabiting four major nurseries in the Vilaine and Loire river estuaries, the Pertuis d'Antioche strait, and the Gironde estuary. Genetic differentiation was not significant for the age 0 - and 1-groups, but was among sub-adult samples ( $\theta W C=0.017 ; P=0.031$ ). Hierarchical analyses of genotypic frequencies by nested multivariate ANOVA using redundancy analysis indicated that northern nurseries of Loire and Vilaine rivers had different patterns of genotypic variation with age than southern nurseries of the Pertuis d'Antioche and Gironde estuaries $(F=1.36 ; P=0.007)$. Bay of Biscay nurseries appeared to be spatially structured between a southern and a northern group that exhibit different genotypic distributions. Genetic drift and gene flow explains this pattern poorly, but a statistical test $(P<0.035)$ suggested that the metallothionein $(M T)$ locus may be significantly impacted by selection in southern estuaries. As metallothionein is involved in heavy-metal detoxification, and southern nurseries are known to be affected by cadmium, this indicates a possible correlation between observed genotypic distributions and some nursery habitat features in sole. Some selective patterns might also be proposed to explain patterns of linkage disequilibrium observed at amylase loci in three of the four nurseries.
\end{abstract}

Keywords: flatfish; juveniles; coastal nurseries; population genetics; EPIC-PCR; genetic drift; selection 


\section{Introduction}

The common sole, Solea solea (L., 1758), is a demersal flatfish of commercial interest in the Eastern Atlantic and in the Mediterranean, with up to 55,000 tons harvested yearly over the last twenty years (http://www.fao.org). The sole is characterized by a type III survivorship curve (i.e. high fecundity and high juvenile mortality), with high number $(>100,000)$ of egg produced by mature females. As for many flatfish, coastal habitats comprise important nurseries for juveniles of the common sole (Koutsikopoulos et al. 1989; Le Pape et al. 2003a). Adult sole spawn during the first months of the year, then pelagic eggs and larvae transform into juvenile benthic fish that concentrate in shallow waters and estuaries from May to July. Juveniles remain in coastal waters for 2 to 3 years until they reach maturity and migrate to deeper waters. Biological and ecological knowledge has accumulated about sole in the Bay of Biscay, specifically to define population dynamics (e.g. recruitment variability) and biological features (e.g. growth, condition factor) of sole across nurseries, and to accurately identify the value of each nursery (Arbault et al. 1986; Koutsikopoulos et al. 1989, 1991, 1995; Dorel et al. 1991; Amara et al. 1994, 2000; Le Pape et al. 2003a, b, c; Gilliers et al. 2006, Laffargue et al. 2007). Genetic knowledge is, however, still relatively scarce, mainly reporting broad-scale panmixia of sole populations in the area (allozymes: Kotoulas et al. 1995; RAPDs: Exadactylos et al. 2003). However, these studies did not fully consider how genetic drift, selection, and gene flow might affect dynamic processes such as colonisation of nurseries by larvae, and might reflect patterns of gene flow across nurseries and/or local selective processes during the juvenile stage. As sole nursery habitats in shallow-water estuaries and bays can be are strongly impacted by human activities (Boutier et al. 2000), an analysis of patterns of genetic variation can also provide insights into how this might influence genetic structure. For example, Marchand et al. (2003) compared populations of European flounder (Platichthys flesus) from contaminated and unpolluted sites of the Bay of Biscay. They revealed correlations between genotypic (allozymic) frequencies, proxies of fitness such as growth rate, and contamination typology. These results suggested different selective pressures on flounder depending on the habitat they colonised. As for sole, sardine (Sardinus pilchardus) is considered a panmictic stock in the Bay of Biscay (Laurent et al. 2006). However, authors demonstrated clinal patterns of genetic variation at some allozymic loci that correlated with physical features such as the distance to the coast or longitude, and with biological features such as age and length of the individuals. Available data therefore suggest that features of marine habitats can be linked to genetic variation in several fish species, both in the Bay of Biscay, as well as in other areas, as revealed by various genetic markers (e.g. Bekkevold et al. 2005 [microsatellites]; HemmerHansen et al. 2007 [microsatellites and one intronic locus]).

In sole, a recent investigation involving intronic markers suggested that local genetic variability among cohorts may exceed genetic variation at wider geographical scales (Rolland et al. 2007). Such observations are classically interpreted as chaotic genetic patchiness (CGP), which is believed to reveal temporal and spatial variation in recruitment. CGP sensu Johnson and Black (1982) refers to cases in which unpatterned (i.e. not geographically structured, not habitat-dependent) genetic variation can be observed at a local scale among freshly recruited larvae/juveniles. Such differentiation among recruits is probably due to the unpredictability of reproduction in the marine environment, which results in a large variance of an individual's contribution to a cohort. This leads to significant local genetic differentiation due to genetic drift within one single adult panmictic population ('sweepstake reproductive success'; Hedgecock 1994; Hellberg et al. 2002, a model that hence has affinities with the ecological match/mismatch hypothesis [Cushing, 1990]). Successive waves of arrival composed of more or less related individuals may also create temporal genetic heterogeneity as reported in various invertebrates (e.g. David and Jarne 1997; Flowers et al. 2002; Virgilio et al. 2006) and vertebrates (e.g. Ruzzante et al. 1996; Planes and Lenfant 2002, Selkoe et al. 2006). CGP might also originate from patterns of gene flow among individuals originating from distinct populations (e.g. So et al. 2006), or be due to 'patterned', habitat dependent selective processes (e.g. Koehn et al. 1980). Such patterning is due to selective, differential survival of genotypes after recruitment (Johnson and Black 1982, 1984). In the acorn barnacle, Véliz et al. (2004) reported that mechanisms explaining temporal genetic differentiation would likely be dependent on the study area, with patterns of genetic differentiation that were mainly explained by genetic drift in one area, whereas selective habitat patterning of genetic variability might predominate in other habitats. Indeed, Véliz et al. (2004) emphasized the importance of studying temporal patterns of genetic variability in several locations, to ensure that mechanisms that affect one population in a given locale (i.e. random drift or selection) might also act in another place. Such examples are rare in the literature, because often only a single local population is considered (Planes and Lenfant 2002, Pujolar et al. 2006). Conversely, the above-mentioned study by 
Marchand et al. (2003) on flounder suggested that selective processes might occur within each estuary but, as sampling occurred only once, the possibility of genotypic divergence due to differential recruitment by larvae cannot be totally excluded.

In the present study, we investigated temporal patterns of genotypic diversity in sole at three intronic markers over four nurseries grounds. Our objective was to decipher the putative role of 'unpatterned' CGP due to random colonisation of nurseries by larvae, and possible habitat-mediated selective pressures, on observed patterns of genetic variation during juvenile growth on each nursery.

\section{Materials and methods}

\subsection{Study area and juvenile nursery fidelity}

Sole spawning and nursery grounds are clearly separated in the Bay of Biscay. Spawning grounds are located 80 to $100 \mathrm{~km}$ from the coast, at depths between 40 to $70 \mathrm{~m}$ (Arbault et al. 1986), whereas the main nursery grounds are located in bays or straits (Pertuis d'Antioche, Vilaine), and in estuaries (Loire, Gironde) (Le Pape et al. 2003a; Fig. 1). Such nurseries can be considered as 'source' habitats, separated by 'sink' habitats where population densities are lower due to absence of large river plumes (e.g. Le Pape et al. 2003a, c). Colonisation of coastal nurseries is a single annual event (Amara et al. 1994) and, as far as we know, no particular behavioural component can be identified. Nurseries are considered not to exchange individuals after settlement (e.g. Dorel et al. 1991; De Pontual et al. 2000). For instance, otolith microchemistry profiles of 0- or 1-group juveniles from the Loire and the Gironde, indicate that juveniles could easily be assigned to their nursery of origin irrespective of their age De Pontual et al. (2000). However, a recent study by Vinagre et al. (2008) in the Tagus estuary (Portugal) also suggests that 0-group individuals harbored high site fidelity, but that site fidelity was consistently lower for the 1-group juveniles. Such a result suggests that gene flow might occur across adjacent sole nurseries separated by a few kilometers $(\approx 10 \mathrm{~km})$, probably once individuals reach a certain size. Note that studies by De Pontual et al. (2000) and Vinagre et al. (2008) did not consider identical spatial scales $(\approx 10 \mathrm{~km} v s>100 \mathrm{~km})$. This suggests that migration, and hence gene flow, could depend on the scale of the study.

\subsection{Sampling}

Four coastal nurseries were sampled using beam trawl, namely, the Vilaine estuary, the Loire estuary, the Pertuis d'Antioche, and the Gironde (mouth of the river Garonne) (Fig. 1). Sampling took place during two successive years $(2000,2001)$ for all sites except the Gironde (2000) (Table 1). Distinct cohorts were sampled (2000: sub-adults [age $2+$, standard length $>22 \mathrm{~cm}$ ] taken before offshore spawning migration; 2001: 0- and 1-groups). Fish were aged using size distributions and, because size classes did not overlap (bimodal distribution), confusion between 0 - and 1-age groups was considered unlikely (data not shown). 0group fishes represented new-settlers. 1-group fish have been interpreted as individuals that settled in 2000 , and had already spent one year on the nursery. In the Gironde estuary, samples represented subadults (age 2+) whereas younger individuals were likely from the 0-group. As only two samples were considered in Gironde instead of three in other areas, the Gironde samples were not considered in subsequent statistical analyses (see below). Thirty individuals were analysed per sample, leading to a total of 330 genotyped individuals.

\subsection{Genetic analyses}

Pieces of preserved muscle (either dried, frozen, or in ethanol) were analysed for genetic variation at three nuclear-DNA intronic loci using EPIC-PCR (exon-primed intron crossing - polymerase chain reaction) following Rolland et al. (2007). This included the intron of the metallothionein gene, and the third intron of pancreatic $\alpha$-amylase genes. Two amylase loci are co-amplified with the same set of primers, as such loci belong to a multigenic family (Bouneau et al. 2003). Further cloning of alleles indicated that sequences of each amylase locus were clearly different and impossible to align (JL Rolland and B Guinand, unpubl. 
results). Size differences in amylase alleles $(\approx 100 \mathrm{bp})$ made misattribution to one or the other locus extremely unlikely.

Deviations from Hardy-Weinberg expectations (HWE) within samples were investigated using Weir and Cockerham's (1984) $f$ using Genetix (v.4.05; Belkhir et al. 2000; http://www.univ-montp2.fr/ genetix/). Test of the null hypothesis of no significant departure from HWE $(f=0)$ was performed by randomly permutating alleles from the original matrix of genotypes using the appropriate procedure in Genetix. Levels of population differentiation were investigated using Weir and Cockerham's (1984) $\theta_{w c}$, an estimator of Wright's (1951) $F_{\mathrm{st}}$. In this study we report mainly on levels of genetic differentiation among samples from the same age class $(0+, 1+$, sub-adults). To investigate patterns of genetic differentiation, we also carried out a nested multivariate ANOVA (MANOVA) by canonical redundancy analysis (classically abbreviated as RDA for Redundancy Discriminant Analysis) using the program NesAnova (Legendre 2002; http://www.bio.umontreal.ca/casgrain/fr/labo/). MANOVA-RDA can test multivariate hypotheses in structured experimental designs (i.e. using main and nested factors of ANOVA models). In our study, sampling sites (Vilaine, Loire and Pertuis d'Antioche) were considered as main factors, and cohorts (sub-adults, 0- and 1groups) as the nested factor. MANOVA-RDA is powerful for balanced data (i.e. equal sample sizes), but much more difficult to handle for unbalanced data (Legendre and Anderson 1999, their Appendix C). This explains why all our samples were initially standardized to thirty individuals, and why Gironde samples were not considered in this particular multivariate analysis (two sub-samples instead of three in other populations). Significance of Fisher's $F$ values were tested under permutations (generally 5000 replicates; see Results for details) included in the NesAnova program, and initially described in Legendre and Anderson (1999).

Using Genetix, we also investigated patterns of linkage disequilibrium (LD) in each sample using the method of Weir (1979). We also performed a multiallelic monolocus neutrality test, the Raufaste-Bonhomme test (hereafter, the RB-test) as described in Arnaud-Haond et al. (2003). This test considers the properties of two multiallelic estimators of $F_{s t}$, those of Weir and Cockerham $\left(\theta_{W c}, 1984\right)$ and of Robertson and Hill $\left(\theta_{R H}\right.$; as defined in Weir and Cockerham, 1984). These estimators have been shown to respond differently to various selection regimes, because rare and frequent alleles are affected differently (Raufaste and Bonhomme 2000). The RB-test represents the difference between $\theta_{w c}$ and $\theta_{R H}$, whose distribution can be approximated by simulations under the null hypothesis of neutrality, in a finite island model, at migration-drift equilibrium. The model assumes that populations belong to the same metapopulation at HWE. The parameters of the simulations (initial allelic frequencies and migration rate) are chosen to fit, at best, the observed values of $\theta_{W C}$ and $\theta_{R H}$. The test-statistic was then calculated with the respective estimated $\theta$-values for each locus in the data set. A significant departure ( $\alpha=0.05$; one-tailed test) of the observed value from the simulated distribution could be interpreted as evidence for non-neutrality of the distribution of allele frequencies at the locus concerned. This test was performed with the program Neutrallelix (http://www.univmontp2.fr/genetix/labo.htm). One thousand replicates were carried out in simulations. Migration rate between local populations in the metapopulation was set to $m=0.10$ (sufficient gene flow to avoid genetic differentiation), and initial allelic frequencies were considered as being homogeneous over the metapopulation.

We tested for Wahlund effect in all individual populations using the program Partition v.2.0 (http://www.univmontp2.fr/ genetix/partition/partition.htm). This program implements the Bayesian method of sample partitioning described in Dawson and Belkhir (2001). Using Markov Chain Monte Carlo procedure, this provides an estimate of the posterior probability that one sample is composed of $k$ panmictic groups. We searched for associated probability that samples which demonstrated significant multilocus departure from HWE were composed of two groups $(k=2)$ vs only one group $(k=1)$. Except once (see Results), we did not expand analysis for further values of $k$, the goal being only to demonstrate whether samples were heterogeneous or not (i.e. composed of several recruiting cohorts as expected in CGP). Thirty thousand observations of the Markov Chain were carried out when estimating posterior probabilities for $k=1$ or 2 . 


\section{Results}

\subsection{Linkage disequilibrium and Hardy-Weinberg equilibrium}

LD between the two amylase loci was significant $(P=0.002)$, but not for other locus comparisons (Table 2$)$. This peculiar disequilibrium was observed in 4 of 11 samples, including 2 over 3 samples from Pertuis d'Antioche, but also in sub-adult samples from the Vilaine and Loire (Table 2).

Only two populations demonstrated significant departures from HWE, sub-adult and 1-group samples from the Loire (Table 1). Single-locus approaches demonstrated heterogeneity among loci for departure of HWE, with locus MT showing 6 out of 11 cases of significant departures whereas locus Am2B3-1 did not (Fig. 2). Wahlund tests suggested that, with the exception of the Loire River, all samples were a panmictic unit (Table 1). The positive Wahlund effect found in the Loire River sample may be viewed as significant $(p(k=2)$ $=0.452$; Table 1). However, further test with $k=3$ and $k=4$ demonstrated that probabilities never departed significantly from equiprobability ( $p=0.33$, and 0.25 , respectively). In such cases, the lowest value of $k$ should be preferred. Hence, significant departures from HWE observed in Fig. 2 were probably not due to a Wahlund effect. As a Wahlund effect is unlikely, observed deviations from HWE may be due to the presence of null alleles, especially at locus $M T$. This hypothesis was also unlikely, because significant heterozygote deficiencies were not observed in all samples and locations (6 over 11 cases; Fig. 2), nor in a larger survey of sole populations using this locus (Rolland et al. 2007). It was therefore difficult to imagine a null allele specific to the Bay of Biscay population. A close examination of Fig. 2 highlights different trends in $f$-values across samples. For example, $f$ values at locus $M T$ demonstrated the same pattern of variation in the Loire and Vilaine estuaries: low $f$ values and no significant departure from HWE for 0-group individuals sampled in 2001, but significantly large $f$ values indicating heterozygote deficiencies in sub-adults and 1-group individuals (Fig. 2). Although no significant departure from HWE was observed, a similar pattern of variation in $f$ values was also observed for Loire and Vilaine samples at locus Am2B3-2 (Fig. 2). Concurrently, the pattern of variation in observed $f$ values was totally distinct for samples from the Pertuis d'Antioche area compared to the pattern in Loire and Vilaine (Fig. 2). Although only two samples were available, patterns observed for the Gironde samples indicated that variation in observed $f$ values was more similar to the pattern of the Pertuis d'Antioche than to the other nurseries areas.

\subsection{Spatial genetic differentiation}

The MANOVA-RDA demonstrated no significant effect of the main factor (site), but a significant effect of the nested factor (cohort within site; $P=0.007$ ) (Table 3). This indicated an absence of population subdivision among Vilaine, Loire, and Pertuis samples, but significantly distinct genotypic patterns within replicated estuary samples (Gironde samples were excluded due to unbalanced pattern in sampling scheme; see Materials and Methods). This result was confirmed by traditional $\theta_{w c}$ estimates that demonstrated no significant differentiation among nurseries $\left(\theta_{w c}=0.007, \theta_{w c}=0.009\right.$, NS; with and without considering the Gironde samples, respectively). Single-locus analysis using MANOVA-RDA found a significant effect of the main factor for locus Am2B3-2 only $(P=0.038)$, but not for other loci (details not shown). Results agreed with traditional estimates of multilocus genetic differentiation such as $\theta_{w c}$, which also did not show evidence for overall genetic differentiation (Rolland et al. 2007). $\theta_{w c}$ for locus Am2B3-2 was significant $\left(\theta_{w c}=0.022\right.$; $P=0.028$ ), whereas estimations for other loci were not (data not shown).

Given that changes in $f$ values were different among nurseries (Pertuis d'Antioche vs Loire and Vilaine; details above and Fig. 2), we recomputed nested MANOVA-RDA for each pair of estuaries. In such pairwise comparisons, the main factor was never significant (results not shown), but the nested factor 'cohort within site' was significant for both the Pertuis d'Antioche-Vilaine and the Pertuis d'Antioche-Loire comparisons ( $P$ $=0.005 ; P=0.014$, respectively; 5000 bootstrap replicates). The nested factor was only marginally significant when using nested MANOVA-RDA among samples of the Vilaine and Loire estuaries $(P=0.061$; 20000 bootstrap replicates in this case to ensure precision of the estimated $P$-value). Hence, these pairwise comparisons demonstrated that patterns of genotypic differentiation between cohorts where distinct between southern Pertuis d'Antioche strait and the northern estuaries (Loire and Vilaine). Conversely, the Loire and Vilaine samples were not genetically distinct from each other, but also did not differ on how genotypic variation was partitioned among sampled cohorts. Overall, results from various nested 
MANOVA's and inspection of trends in observed $f$ values (Fig. 2) suggest that northern (Loire + Vilaine) and southern (Pertuis d'Antioche + Gironde) samples differed in their genotypic compositions.

\subsection{Temporal genetic differentiation}

Multilocus genetic differentiation among samples from the same age-class showed increasing values of $\theta_{w c}$, associated with significant differentiation among sub-adult samples (among 0-group samples: $\theta_{w c}=0.0099$, $P=0.080$; among 1-group samples: $\theta_{w c}=0.0106, P=0.083$; among sub-adults samples without Gironde sample: $\theta_{w c}=0.0125, P=0.032 ;$ among sub-adults samples with Gironde sample: $\theta_{w c}=0.0174 ; P=$ 0.031).

\subsection{RB-test}

Finally, the RB-test revealed that locus Am2b3-2 could have been affected by selection $(P=0.017)$ when all eleven samples were considered in the metapopulation (excluding Gironde samples did not change the outcome of the test; $P=0.021$ ). Other loci were not significant at the nominal $\alpha=0.05$ level (locus $M T: P=$ 0.113; locus Am2B3-1: $P=0.446)$. As results from RDA-MANOVA suggested that northern and southern samples may have distinct genotypic compositions (above), we also tested for selection after pooling the northern Loire and Vilaine samples on the one hand, and the southern Gironde and Pertuis d'Antioche on the other hand. Only locus $M T$ provided significant results $(P=0.032 ; P=0.035$, when excluding Gironde samples from pooled southern populations), indicating potential for selection acting on this locus.

\section{Discussion}

Prior to discussing the results, it is important to note that, in this study, sub-adults were caught in 2000 but the other age-classes in 2001. We have not, therefore, observed the development of genetic differentiation in a single generation over time, but compared genetic differentiation over two generations. Nevertheless, sub-adults fished in $\mathbf{2 0 0 0}$ that reached maturity when leaving the nurseries would contribute to the 0-group juveniles that were fished on nurseries in 2001. This leads to 'temporal connectivity' among some samples but not among others. Results should be interpreted with appropriate caution, in light of this particular sampling scheme.

\subsection{Genetic differentiation in Bay of Biscay sole: departure from panmixia}

Population genetic studies by Kotoulas et al. (1995), Exadactylos et al. (2003), and Rolland et al. (2007) using various different genetic markers indicated panmixia of sole populations in the Bay of Biscay. Our results strengthen this view as the site effect was not significant in MANOVA-RDA (Table 3) and in $\theta_{w c}$ multilocus estimates $\left(\theta_{w c}=0.007, N S\right)$. Our results indicate that genetically distinct subpopulations (subadults) in 2000 that subsequently reached maturity would contribute to panmictic colonisation of nurseries by larvae in $2001\left(\theta_{w c}=0.0099, P=0.080\right)$. This supports ecological observations on the sole life-cycle, which indicate mixing of eggs over offshore spawning grounds (Arbault et al. 1986; Koutsikopoulos et al. 1995).

Nevertheless, genetic differentiation was not significant in the 0- and 1-groups, but was significant among sub-adults $\left(\theta_{w c}=0.0174 ; P=0.031\right)$, suggesting that panmixia might be modulated across age-classes. A panmictic model is also challenged by the significant differentiation among genotypic distributions within sites (Table 3). Despite lack of temporal connectivity among samples, the results suggest that differentiation might arise over time as larvae and then juveniles inhabit nurseries. Such differentiation could result from low recruitment for one generation, with the other generations possibly not affected. For example, low recruitment over each nursery would cause low local effective population size and favour genetic drift, so promoting the spatial genetic isolation observed among sub-adults samples. Seasonal egg and larval production is often mistimed with favourable conditions for survival in marine fishes (match-mismatch hypothesis; Cushing 1990), and successful recruitment in sole would depend on planktonic survival, condition at metamorphosis, and further productivity of the nursery at the onset of colonisation. This could lead to CGP originating from one panmictic population provided that a quite small number of progenitors are 
finally involved in local recruitment. In another generation, such local effective population sizes could be higher when recruiting another cohort, drift then being less likely, so producing genetic homogeneity over nurseries as observed for the 0- and 1-groups. Nevertheless, in the Bay of Biscay sole, eggs and larvae are not considered to be the most important bottlenecks to recruitment (Koutsikopoulos and Lacroix 1992). Metamorphosis is not considered a limiting factor either (Amara et al. 2000; Amara and Galois 2004), but it is access to the benthic environment that appears to be the key to successful recruitment (e.g. Le Pape et al. 2003c; Couturier et al. 2007). Proxies of juvenile survival (density estimates) indicated that such variability is dampened in the Bay of Biscay sole (Le Pape et al. 2003c; Désaunay et al. 2006). Drift is therefore unlikely to explain temporal patterns of genetic differentiation in Bay of Biscay sole. Hence, despite the lack of full 'temporal connectivity' across our samples, CGP alone can probably not explain the observed patterns of genetic differentiation.

If drift is unlikely, kin structure (relatedness; i.e. settlement of related individuals from several 'families' in each area) does not arise in sole. Relatedness of individuals would contribute to a Wahlund effect, and increase $f$ in 0-group samples (Hoarau et al. 2005). Kin structure as the source of a Wahlund effect is not supported by our results for several reasons. Firstly, the partitioning study did not indicate that samples were composed of a mix of 'families' (Table 1). However, the reliability of partition detection in the context of panmixia are questionable, and the detection of relatedness would require more polymorphic loci (Blouin et al. 1996). Secondly, any pattern of relatedness would be more accurately detected among the 0-group individuals, but only the Pertuis d'Antioche sample at locus $M T$ demonstrated a significant value of $f$ for individuals of the 0-group (Fig. 2). Other significant values concentrate in 1-group and sub-adult individuals (Fig. 2). Finally, if genotypic structure of cohorts varied among sites because of site-specific patterns in relatedness, we should expect a significant effect of this factor in nested MANOVA-RDA for each pairwise comparison (i.e. genotypic distribution observed at each nursery would be specific because patterns of relatedness effect would be nursery-specific). Despite an almost significant probability estimate $(P=0.061)$, the Vilaine and Loire estuaries tended to demonstrate similarities in genotypic distributions rather than strict independence. Similar genotypic distributions among estuaries rules out the relatedness hypothesis as individuals from the Loire and the Vilaine are not the progeny of the same low number of progenitors. This suggests gene flow or similar selective pressures among northern Bay of Biscay nurseries. Hence, arguments accumulate against a role for genetic drift and 'unpatterned' CGP.

Fig. 2 highlights shared patterns of co-variation in genotypic distributions among Vilaine and Loire samples, especially at locus $M T$ (i.e. when one sample from one estuary presented a high [low] $f$ at a given locus, the corresponding sample in the other estuary also often displayed a comparable $f$ ). Concurrently, among subadult samples, values of $f$ at loci $M T$ and Am2B3-2 for the Vilaine and Loire nurseries were in opposition with the values observed in Pertuis d'Antioche and Gironde samples (Fig. 2). Similarity among the set of northern nurseries as opposed to the southern one(s) indicates that genotypic exchanges are geographically "patterned" in sole. This also suggests gene flow or similar selective pressures among northern Bay of Biscay nurseries.

\subsection{Gene flow and selection among and within northern and southern sets of nurseries}

Revealing the respective roles of gene flow versus selection is always difficult. In sole, northern nurseries are physically connected through freshwater inputs of the Loire's river plume in the Bay of Vilaine, and a similar phenomenon is observed for the southern Garonne and Pertuis d'Antioche nurseries (see Lazure and Jegou 1998, and references therein). This may facilitate the exchange of individuals among neighbouring nurseries, explaining the similar genotypic distributions observed for the Loire and the Vilaine (see above). On the other hand, waters of the Loire and Garonne rivers do not mix, their river plumes are never connected (Lazure and Jegou 1998). As the southern and northern nurseries are separated by unsuitable habitats for juveniles (Fig. 1), this makes gene flow among the northern and southern nurseries unlikely, and so explains the distinct genotypic distributions between them. Otolith microchemistry also found no evidence for exchange of individuals between the Loire and the Gironde (De Pontual et al. 2000). Overall, this implies that juvenile migration among nurseries is a scale-dependent process, which would explain why genotypic distributions are similar at a local scale where juvenile migration is possible, but distinct at a wider scale where it is not. At the scale of a few kilometers, Vinagre et al. (2008) suggested that migration across nurseries is also dependent on age, with 1-group sole juveniles exhibiting less site fidelity that the 0-group. If we accept that the ability of juveniles to migrate is age-dependent, this may explain why the Wahlund effect measured by $f$-values was sometimes larger in the 1- and 2-group juveniles, because these are composed of distinct groups of individuals, and also explain the patterns of co-variation previously observed among each set of nurseries (Fig. 2). Nevertheless, if the results support a role for differential 
gene flow among nurseries, gene flow alone cannot explain why sub-adults were genetically differentiated in our study.

The proposition that differential selection might shape observed genotypic distributions across cohorts in the southern and northern nurseries can be supported by further interpretation of the genetic results, in light of existing environmental knowledge. The RB-test indicated that two loci might potentially be responding to selection: locus Am2B3-2 when samples were considered separately, and locus $M T$ when northern and southern samples were pooled. These loci demonstrated significant deviations from HWE (Fig. 2), suggesting that results from the RB-test and patterns of genotypic distributions that underly $f$ values are linked. Metallothionein genes are known to be strongly involved in detoxification of cadmium (e.g. Roesijadi 1996; Solé et al. 2004), and the Gironde estuary is polluted by heavy metals, principally cadmium, zinc and copper (Grousset et al. 1999; RNO 2004a). Such pollutants are not restricted to the estuary, but also strongly affect the neighbouring Charente Straits (Boutier et al. 2000). By contrast with these southern nurseries, the Loire estuary has a diffuse pollution dominated by polycyclic aromatic hydrocarbons and polychlorinated biphenyls (RNO 2004b). Organochlorine pesticides are the major contaminants of the bay of Vilaine (Forget et al. 2003). Hence, the northern and southern nurseries experience different ecotoxicological stresses, and different potential selective pressures on genotypic distributions at $M T$ locus are not unlikely. Allozyme data indicating pollution-related shifts in the distribution of particular genotypes have been reported for flounder in French Atlantic estuaries, including differences between the Loire and Gironde estuaries (Marchand et al. 2003). Furthermore, genetic variation at the MT locus consists of variation at two short mononucleotidic microsatellites (poly-T) present in the intronic sequence of the gene (J.-L. Rolland, B. Guinand, F. Bonhomme, unpublished). Such variations are known to potentially affect exon splicing of numerous genes, leading to aberrant functioning when facing different challenges (e.g. Niksic et al. 1999). Further studies are necessary to investigate this phenomenon.

Unlike for the MT locus, the current understanding of fish amylases is incomplete (Krogdahl et al. 2005), and molecular or genetic analyses of amylase genes in marine teleosts are scarce (Douglas et al. 2000; Ma et al. 2004). The adaptive significance of peculiar genotypes have not yet been reported in fishes, although there has been work on one marine species (e.g. Prudence et al. 2006). Nevertheless, despite the limited knowledge on amylase, the pattern of LD between the two co-amplified amylase genes deserves some attention (Table 3) because these patterns may reflect an impact of selection. Thus, it is interesting that significant LD were observed among samples of sub-adults in most populations except Gironde, but not among 0 - and most 1-group fish. This suggests that individuals which survived at least two winters possessed particular allelic associations for amylase loci (Table 3). Such an epistatic interaction between amylase loci during the course of development has been investigated in Drosophila melanogaster, and indicated that preferential allelic associations among loci was an adaptive response to specific feeding environments encountered by local populations (e.g. Araki et al. 2005, and references therein). Since linkage disequilibrium among amylase loci was predominantly found in 1-group juveniles and sub-adults, but not in the 0-group, it would be possible to interpret the LD at those loci as arising by a similar foodweblinked process. Thus, significance of the RB-test and significant genetic differentiation $\left(\theta_{W C}=0.022 ; P=\right.$ 0.028 ) at locus Am2B3-2 can be interpreted as supporting selective pressures occurring on the amylase in sole.

\subsection{Future directions}

Overall, the results presented here provide a clearer picture of spatio-temporal patterns of genetic variation in the Bay of Biscay sole. They allow us to propose a model synthesising current understanding of sole population genetics (Fig. 3). This scheme involves different nurseries of different qualities (e.g., source and sink) and transient processes (migration/gene flow across nurseries when possible; relative importance of drift and selection across generations that could potentially turn a source habitat into a sink and vice-versa). Support for the model proposed in Fig. 3 will be provided by further investigation. In the context of stock management, it would be important to estimate the contributions of the different nurseries or groups of nursery to the spawning population, to assess more precisely the contribution of each nursery to successive generations. This would provide better understanding of the connectivity between the juvenile and the adult phases (Able 2005), and of the value of each nursery (Beck et al. 2001). Concurrently, as estuarine habitats and associated nurseries are highly impacted by both anthropological and natural factors (Roessig et al. 2004), better knowledge of the genes involved in responses to stress (e.g. temperature, pollutants, hypoxia) in each habitat would provide essential insights into the potential genetic bases of adaptation in sole. In flatfishes, gene expression data in the natural environment have been investigated for the American winter 
flounder (Straub et al. 2004) and the European flounder (Williams et al. 2003, 2005; Marchand et al. 2006), and are certainly adaptive (Larsen et al. 2007). Indeed, fish are increasingly recognised as excellent models for environmental genomics (Cossins and Crawford 2005), and the sole provides an interesting species upon which to investigate links between phenotypes, genotypes, and fitness.

\section{Acknowledgements}

This work was supported by the IFREMER Programme "Défi Golfe de Gascogne". We are grateful to F. Lagardère, C. Gilliers, E. Durieux, O. Le Pape, G. Claireaux, M. Hassan and D. Turpin for support, and in particular to $Y$. Désaunay and the technical staff of IFREMER for providing most of the samples used in this study. We are also grateful to reviewers for suggesting improvements to the manuscript, and to D. McKenzie for revising the English text. This is publication ISEM 2008-XXX (Institut des Sciences de l'Evolution de Montpellier, UMR 5554, CNRS).

\section{References}

Able, K.W. 2005. A re-examination of fish estuarine dependence: evidence for connectivity between estuarine and ocean habitats. Estuarine, Coastal and Shelf Science 64, 5-17.

Amara, R., Galois, R. ; 2004. Nutritional condition of metamorphosing sole: spatial and temporal analyses. Journal of Fish Biology 61: 72-88.

Amara, R.., Désaunay, Y.., Lagardère, F., 1994. Seasonal variation in growth of larval sole, Solea solea (L.) and consequences on the success of larval immigration. Netherlands Journal of Sea Research 32, 287298.

Amara, R., Lagardère, F., Désaunay, Y., Marchand, J., 2000. Metamorphosis and estuarine colonisation in the common sole, Solea solea (L.): implications for recruitment regulation. Oceanologica Acta 23, 469-483.

Araki, H., Yoshizumi, S., Inomata, N., Yamazaki, T., 2005. Genetic coadaptation of the amylase gene system in Drosophila melanogaster: evidence for the selective advantage of the lowest $A M Y$ activity and of its epistatic genetic background. Journal of Heredity 96, 388-395.

Arbault, S., Camus, P., Le Bec, C., 1986. Estimation du stock de sole (Solea vulgaris, Quensel) dans le golfe de Gascogne à partir de la production d'œufs. Journal of Applied Ichthyology 4, 145-156.

Arnaud-Haond, S., Bonhomme, F., Blanc, F., 2003. Large discrepancies in differentiation of allozymes, nuclear and mitochondrial DNA loci in recently founded Pacific populations of the pearl oyster Pinctada margaritifera. Journal of Evolutionary Biology 16, 388- 396.

Beck, M.W., Heck, K.L., Able, K.W., Childers, D.L., Eggleston, D.B., Gillanders, B.M., Halpern, B., Hays, C.G., Hoshino, K., Minello, T.J., Orth, R.J., Sheridan, P.F., Weinstein, M.P., 2001. The identification, conservation, and management of estuarine and marine nurseries for fish and invertebrates. BioScience 51 , 633-641.

Bekkevold, D., André, C., Dahlgren, T.G., Clausen, L.A.W., Torstensen, E., Mosegaard, H., Carvalho, G.R., Christensen, T.B., Norlinder, E., Ruzzante, D.E., 2005. Environmental correlates of population differentiation in Atlantic herring. Evolution 59, 2656-2668.

Belkhir, K., Borsa, P., Goudet, J., Chikhi, L., Bonhomme, F., 2001. Genetix v.4.03, Logiciel sous Windows ${ }^{\mathrm{TM}}$ pour la Génétique des Populations. Laboratoire Génome et Population, Université Montpellier 2, Montpellier.

Bouneau, L., Lardier, G., Fischer, C., Ronsin, M., Weissenbach, J., Bernot, A., 2003. Analysis of $148 \mathrm{~kb}$ of genomic DNA of Tetraodon nigroviridis covering an amylase gene family. DNA Sequences 14, 1-13.

Boutier, B., Chiffoleau, J.-F., Gonzalez, J.L., Lazure, P., Auger, D., Truquet, I., 2000. Influence of the Gironde estuary outputs on cadmium concentrations in the coastal waters: consequences on the MarennesOléron bay (France). Oceanologica Acta 23 (Suppl.), 745-757.

Couturier, C.S., Rouault, A., McKenzie, D., Galois, R., Robert, S., Joassard, L., Claireaux, G., 2007. Effects of water viscosity upon ventilation and metabolism of a flatfish, the common sole Solea solea (L.). Marine Biology 152, 803-814.

Cossins, A.R., Crawford, D.L., 2005. Fish as models for environmental genomics. Nature Reviews Genetics 6, 324-333. 
Cushing, D.H., 1990. Plankton production and year class and year class strength in fish populations: an update of the match/mismatch hypothesis. Advances in Marine Biology 26, 249-293.

David, P., Jarne, P., 1997. Context-dependent survival differences among electrophoretic genotypes in natural populations of the marine bivalve Spisula ovalis. Genetics 146, 335 - 344.

Dawson, K.J., Belkhir, K., 2001. A Bayesian approach to the identification of panmictic populations and the assignment of individuals. Genetical Research 78, 59-77.

De Pontual, H., Lagardère, F., Troadec, H., Batel, A., Désaunay, Y., Koutiskopoulos, C., 2000. Otoliths imprinting of sole (Solea solea) from the Bay of Biscay: a tool to discriminate individuals from nursery origins? Oceanologica Acta 23, 497-513.

Désaunay, Y., Guérault, D., Le Pape, O., Poulard, J.-C., 2006. Change in occurrence and abundance of northern/southern flatfishes over a 20-year period in a coastal nursery area (Bay of Vilaine) and on the eastern continental shelf of the Bay of Biscay. Scientia Marina, 70 (Suppl. 1): 193-200.

Dorel, D., Koutsikopoulos, C., Désaunay, Y., Marchand, J., 1991. Seasonal distribution of young sole (Solea solea (L.)) in the nursery ground of the Bay of Vilaine (Northern Bay of Biscay). Netherlands Journal of Sea Research. 27, 297-306.

Douglas, S.E., Mandla, S., Gallant, J.W., 2000. Molecular analysis of the amylase gene and its expression during development in the winter flounder, Pleuronectes americanus. Aquaculture 190, 247-260.

Exadactylos, A., Geffen, A.J., Panagiotaki, P., Thorpe, J.P., 2003. Population structure of Dover sole Solea solea: RAPD and allozyme data indicate divergence in European stocks. Marine Ecology Progress Series 246, 253-264.

Flowers, J.M., Schroeter, S.C., Burton, R.S., 2002. The recruitment sweepstakes has many winners: genetic evidence from the sea urchin Strongylocentrotus purpuratus. Evolution, 56, 1445-1453.

Forget, J., Beliaeff, B., Bocquené, G., 2003. Acetylcholinesterase activity in copepods (Tigriopus brevicornis) from the Vilaine River estuary, France, as a biomarker of neurotoxic contaminants. Aquatic Toxicology 62, 195-204.

Gilliers, C., Le Pape O., Désaunay Y., Morin J., Guérault D., Amara R., 2006. Are growth and density quantitative indicators of essential fish habitat quality? An application to the common sole Solea solea nursery grounds. Estuarine, Coastal and Shelf Science 69, 96-106.

Grousset, F.E., Jouanneau, J.M., Castaing, P., Lavaux, G., Latouche, C., 1999. A 70 year record of contamination from industrial activity along the Garonne River and its tributaries (SW France). Estuarine, Coastal and Shelf Science 48, 401-414.

Hedgecock, D., 1994. Does variance in reproductive success limit effective population size of marine organisms? In: Genetics and Evolution of Aquatic Organisms (A. R. Beaumont, ed.), pp. 122-134. Chapman \& Hall, London.

Hedgecock, D., Launey, S., Pudovkin, A.I., Naciri, M., Lapègue, S., Bonhomme, F., 2007. Small effective number of parents $\left(N_{b}\right)$ inferred for a naturally spawned cohort of juvenile European flat oysters Ostrea edulis. Marine Biology 150, 1173-1182.

Hellberg, M.E., Burton, R.S., Neigel, J.E., Palumbi, S.R., 2002. Genetic assessment of connectivity in marine populations. Bulletin of Marine Science 70 (Suppl.): 273-290.

Hemmer-Hansen, J., Nielsen, E.E., Frydenberg, J., Loeschke, V., 2007. Adaptive divergence in a high gene flow environment: Hsc70 variation in the European flounder (Platichthys flesus L.). Heredity. doi:10.1038/sj.hdy.6801055

Hoarau, G., Boon, E., Jongma, D.N., Ferber, S., Palsson, J., van der Veer, H.W., Rijnsdorp, A.D., Stam, W.T., Olsen, J.L., 2005. Low effective population size and evidence for inbreeding in an overexploited flatfish, plaice (Pleuronectes platessa L.). Proceedings of the Royal Society of London: Biological Sciences 272, 497-504.

Johnson, M.S., Black, R., 1982. Chaotic genetic patchiness in an inter-tidal limpet, Siphonaria sp. Marine Biology 70, 157-164.

Johnson, M.S., Black, R., 1984. Patterns beneath the chaos: the effect of recruitment on genetic patchiness in an intertidal limpet. Evolution 38, 1371-1383.

Koehn, R.K., Newell, R.I.E., Immermann, F., 1980. Maintenance of an aminopeptidase allele frequency cline by natural selection. Proceedings of the National Academy of Sciences of the United States of America 77, 5385-5389.

Kotoulas, G., Bonhomme, F., Borsa, P., 1995. Genetic structure of the common sole Solea vulgaris at different geographic scales. Marine Biology 122, $361-375$.

Koutsikopoulos, C., Lacroix, N., 1992. Distribution and abundance of sole (Solea solea (L.)) eggs and larvae in the Bay of Biscay between 1986 and 1989. Netherlands Journal of Sea Research 29, 81-91. 
Koutsikopoulos, C., Désaunay, Y., Dorel, D., Marchand, J., 1989. The role of coastal areas in the life history of sole (Solea solea (L.)) in the bay of Biscay. Scientia Marina 53, 567-575.

Koutsikopoulos, C., Fortier, L., Gagné, J., 1991. Cross-shelf dispersion of Dover sole eggs and larvae (Solea solea) in Biscay Bay and recruitment to inshore nurseries. Journal of Plankton Research 13, 923945.

Koutsikopoulos, C., Dorel, D., Désaunay, Y., 1995. Movement of sole Solea solea (L.) in the Bay of Biscay: coastal environment and spawning migration. Journal of the Marine Biological Association of the United Kingdom 75, 109-126.

Krogdahl, A.., Hemre, G.I., Mommsen, T.P., 2005. Carbohydrates in fish nutrition: digestion and absorption in postlarval stages. Aquaculture Nutrition 11, 103-122.

Laffargue, P., Lagardère, F., Rijnsdorp, A.D., Fillon, A., Amara, R., 2007. Growth performances of juvenile soles Solea solea under environmental constraints of embayed nursery areas. Aquatic Living Resources 20 , 213-221.

Larsen,P.F., Nielsen, E.E., Williams, T.D., Hemmer-Hansen, J., Chipman, J.K., Kruhøffer, M., Grønkjaer, P., George, S.G., Dirskjøt, L., Loeschke, V., 2007. Adaptive differences in gene expression in European flounder (Platichthys flesus). Molecular Ecology 16, 4674-4683.

Laurent, V., Voisin, P., Planes, S., 2006. Genetic clines in the Bay of Biscay provide estimates of migration for Sardina pilchardus. Journal of Heredity 97, 81-88.

Lazure, P., Jegou, A.M., 1998. 3D modelling of seasonal evolution of Loire and Gironde plumes on Biscay Bay continental shelf. Oceanologica Acta 21, 165-177.

Legendre, P., 2002. Nested anova user's guide. Département de sciences biologiques, Université de Montréal. 26 pages.

Legendre, P., Anderson, M.J., 1999. Distance-based redundancy analysis: testing multispecies responses in multifactorial ecological experiments. Ecological Monographs 69, 1-24.

Le Pape, O., Chauvet, F., Mahévas, S., Lazure, P., Guérault, D., Désaunay, Y., 2003a. Quantitative description of habitat suitability for the juvenile common sole (Solea solea, L.) in the Bay of Biscay (France) and the contribution of different habitats to the adult population. Journal of Sea Research 50, 139-149.

Le Pape, O., Holley, J., Guérault, D., Désaunay, Y., 2003b. Quality of coastal and estuarine essential fish habitats: estimations based on the size of juvenile common sole (Solea solea L.). Estuarine, Coastal and Shelf Science 58, 793-803.

Le Pape, O., Chauvet, F., J., Désaunay, Y., Guérault, D., 2003c. Relationship between interannual variations of the river plume and the extent of nursery grounds for the common sole (Solea solea, L.) in Vilaine Bay. Effects on recruitment variability. Journal of Sea Research 50, 177-185.

Ma P, Liu Y, Reddy KP, Chan WK, Lam TJ. 2004. Characterization of the seabass pancreatic $\alpha$-amylase gene and promoter. General and Comparative Endocrinology 137, 78-88.

Marchand, J., Tanguy, A., Laroche, J., Quiniou, L., Moraga, D., 2003. Responses of European flounder Platichthys flesus populations to contamination in different estuaries along the Atlantic coast of France. Marine Ecology Progress Series 260, 273- 284.

Marchand, J., Tanguy, A., Charrier, G., Quiniou, L., Plee-Gauthier, E., Laroche J., 2006. Molecular identification and expression of differentially regulated genes of the European flounder, Platichthys flesus, submitted to pesticide exposure. Marine Biotechnology 8, 275-294.

Niksic, M., Romano, M., Buratti, E., Pagani, F., Baralle F.E., 1999. Functional analysis of cis-acting elements regulating the alternative splicing of human CFTR exon 9. Human Molecular Genetics 8, 23392349.

Planes, S., Lenfant, P., 2002. Temporal change in the genetic structure between and within cohorts of a marine fish, Diplodus sargus, induced by a large variance in individual reproductive success. Molecular Ecology 11, 1515-1524.

Prudence, M., Moal, J., Boudry, P., Daniel, J.-Y., Quéré, C., Jeffroy, F., Mingant, C., Ropert, M., Bédier, E., Van Wormhoudt, A., Samain, J.-F., Huvet, A., 2006. An amylase gene polymorphism is associated with growth differences in the Pacific cupped oyster Crassostrea gigas. Animal Genetics 37, 348-351.

Pujolar, J.M., Maes, G.E., Volckaert, F.A.M., 2006. Genetic patchiness among recruits in the European eel, Anguilla anguilla. Marine Ecology Progress Series 307, 209-217.

Ramzi, A., Arino, O., Koutsikopoulos, C., Boussouar, A., Lazure, P., 2001. Modelling and numerical simulations of larval migration of the sole (Solea solea (L.)) of the Bay of Biscay. Part 1: modelling. Oceanologica Acta 24, 101-112.

Raufaste, N., Bonhomme, F., 2000. Properties of bias and variance of two multiallelic estimators of FST . Theoretical Population Biology 57, 285-296. 
RNO (Réseau National d'Observation) 2004a. Résultats de la surveillance de la qualité du milieu marin littoral, Départements: Morbihan, Loire-Atlantique, Vendée. Ifremer - Laboratoire Côtier d'Arcachon. 77pp. (available at : http://www.ifremer.fr/envlit/pdf/surveillancepdf/bull2004/bul_mpl_2004.pdf).

RNO (Réseau National d'Observation) 2004b. Résultats de la surveillance de la qualité du milieu marin littoral, Départements: Gironde, Landes, Pyrénées Atlantiques. Ifremer - Station de Nantes 115pp. (available at: http://www.ifremer.fr/envlit/pdf/surveillancepdf/bull2004/bul_ar_2004.pdf).

Roesijadi, G., 1996. Metallothionein and its role in toxic metal regulation. Comparative Biochemistry and Physiology 113C, 117-123.

Roessig, J.M., Woodley, C.M., Cech Jr., J.J., Hansen, L.J., 2005. Effects of global climate change on marine and estuarine fishes and fisheries. Reviews in Fish Biology and Fisheries 14: 251-275.

Ruzzante, D.E., Taggart, C.T., Cook, D., 1996. Spatial and temporal variation in the genetic composition of a larval cod (Gadus morhua) aggregation: cohort contribution and genetic stability. Canadian Journal of Fisheries and Aquatic Sciences 53, 2695-2705.

Selkoe, K.A., Gaines, S.D., Caselle, J.E., Warner, R.R., 2006. Current shifts and kin aggregation explain genetic patchiness in fish recruit. Ecology 87, 3082-3094.

Smedbol, R.K., McPherson, A., Hansen, M.M., Kenchington, E., 2002. Myths and moderations in marine "metapopulations"? Fish and Fisheries 3, 20-35.

So, N., Maes, G., Volckaert, F.A.M., 2006. Intra-annual genetic variation in the downstream larval drift of sutchi catfish (Pangasianodon hypophthalmus) in the Mekong river. Biological Journal of the Linnean Society 89, 719-728.

Solé, M., Potrykus, J., Fernández-Díaz, C., Blasco, J., 2004. Variations on stress defences and metallothionein levels in the Senegal sole, Solea senegalensis, during early larval stages. Fish Physiology and Biochemistry 30, 57-66

Straub, P.F., Higham, M.L., Tanguy, A., Landau, B.J., Phoel, W.C., Hales Jr., L.S., Thwing, T.K.M., 2004. Suppression subtractive hybridization cDNA libraries to identify differentially expressed genes from contrasting fish habitats. Marine Biotechnology 6, 386-399.

Véliz, D., Bourget, E., Bernatchez, L., 2004. Regional variation in the spatial scale of selection at $M P I^{*}$ and $\mathrm{GPI}^{*}$ in the acorn barnacle Semibalanus balanoides (Crustacea). Journal of Evolutionary Biology 17, 953966.

Vinagre, C., Salgado, J., Costa, M.J., Cabral, H.N., 2008. Nursery fidelity, food web interactions and primary sources of nutrition of the juveniles of Solea solea and S. senegalensis in the Tagus estuary (Portugal): a stable isotope approach. Estuarine, Coastal and Shelf Science 76, 255-268.

Virgilio, M., Backeljau, T., Abbati, M., 2006. Mitochondrial DNA and allozyme patterns of Hediste diversicolor (Polychaeta: Nereididae): the importance of small scale genetic structuring. Marine Ecology Progress Series 326, 157-165.

Weir, B.S., 1979. Inference about linkage disequilibrium. Biometrics 31, 235-254.

Weir, B.S., Cockerham, C.C., 1984. Estimating F-statistics for the analysis of population structure. Evolution 38, $1358-1370$.

Williams, T.D., Gensberg, K., Minchin, S.D., Chipman, J.K., 2003. A DNA expression array to detect toxic stress response in European flounder (Platichthys flesus). Aquatic Toxicology 65, 141-157.

Williams, T.D., Diab, A.M., George, S.G., Godfrey, R.E., Sabine, V., Conesa, A., Minchin, S.D., Watts, P.C., Chipman, J.K., 2006. Development of the GENIPOL European flounder (Platichthys flesus) microarray and determination of temporal transcriptional response to cadmium at low dose. Environmental Science and Technology 40, 6479-6488.

Wright, S., 1951. The genetical structure of populations. Annals of Eugenics 15, 323-354. 
Tables

Table 1:

\begin{tabular}{cccccc}
\hline year & pop. & multilocus $f$ & $\pm 95 \% \mathrm{Cl}$ & $p(k=1)$ & $p(k=2)$ \\
& & & & - & - \\
2000 & Vilaine SubAd & 0.194 & $(-0.029-0.393)$ & 0.794 & 0.206 \\
2001 & Vilaine 0 & -0.018 & $(-0.181-0.115)$ & 0.990 & 0.010 \\
$"$ & Vilaine 1 & 0.101 & $(-0.077-0.233)$ & 0.985 & 0.015 \\
2000 & Loire SubAd & 0.253 & $(0.064-0.404)$ & 0.548 & 0.452 \\
2001 & Loire 0 & 0.016 & $(-0.167-0.181)$ & 0.989 & 0.011 \\
$"$ & Loire 1 & 0.240 & $(0.044-0.408)$ & 0.969 & 0.031 \\
2000 & Antioche SubAd & -0.037 & $(-0.204-0.107)$ & 0.988 & 0.012 \\
2001 & Antioche 0 & 0.084 & $(-0.124-0.258)$ & 0.990 & 0.010 \\
$"$ & Antioche 1 & 0.118 & $(-0.041-0.249)$ & 0.982 & 0.018 \\
2000 & Gironde SubAd & -0.067 & $(-0.218-0.043)$ & 0.975 & 0.025 \\
$"$ & Gironde Juv & 0.048 & $(-0.102-0.158)$ & 0.985 & 0.015 \\
& & & & & \\
\hline
\end{tabular}

Table 1: Multilocus estimates of $f( \pm 95 \% \mathrm{Cl}$; significant value are indicated by italics) for each sample, and probability that each sample is made of $k=1$ or $k=2$ panmictic or quasi-panmictic groups using Partition. 
Table 2:

All samples

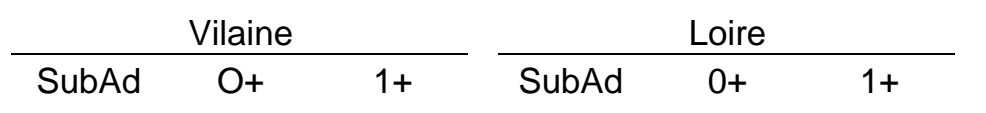

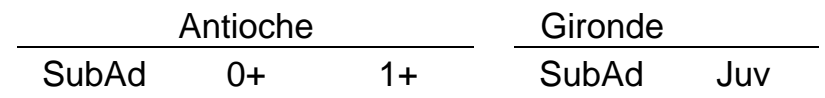

\begin{tabular}{ccccccccccccccc}
\hline$M T-A m 2 B 3-1$ & 0.356 & 0.346 & 0.379 & 0.189 & 0.489 & 0.476 & 0.227 & 0.358 & 0.694 & 0.655 & 0.366 & 0.446 \\
$M T-A m 2 B 3-2$ & 0.354 & 0.433 & 0.993 & 0.913 & 0.026 & 0.084 & 0.068 & 0.932 & 0.938 & 0.045 & 0.400 & 0.827 \\
$\begin{array}{c}\text { Am2B31- } \\
\text { Am2B3-2 }\end{array}$ & 0.002 & 0.013 & 0.903 & 0.263 & 0.002 & 0.257 & 0.191 & 0.037 & 0.098 & 0.025 & 0.121 & 0.217 \\
\hline
\end{tabular}

Table 2: $P$-values $(\alpha=0.05)$ for significant linkage disequilibrium sensu Weir $(1979)$ for each pair of locus, in each sample. Significant values are given in italics. 
Table 3:

\begin{tabular}{cccccc}
\hline Source of variation & $d f$ & Sum of Squares Mean Square & $F$ & $p$ - value \\
\hline $\begin{array}{c}\text { Main factor } \\
\text { (site) }\end{array}$ & 2 & 0.00542 & 0.00271 & 0.90840 & 0.622 \\
$\begin{array}{c}\text { Nested factor } \\
\text { (cohorts within site) }\end{array}$ & 6 & 0.01790 & 0.00298 & 1.35943 & $0.007^{\star *}$ \\
Within subgroups & 216 & 0.47405 & 0.00219 & & \\
$\quad$ Total & 224 & 0.49737 & & & \\
\hline
\end{tabular}

Table 3: Results from hierarchical (nested) MANOVA-RDA across samples from the Vilaine and Loire estuaries, and Pertuis d'Antioche Straits. Gironde samples were not included as such analysis necessitate balanced data (Legendre and Anderson 1999). Significance of $F$ was assessed by permutations (5000 replicates). 


\section{Figures}

Fig. 1

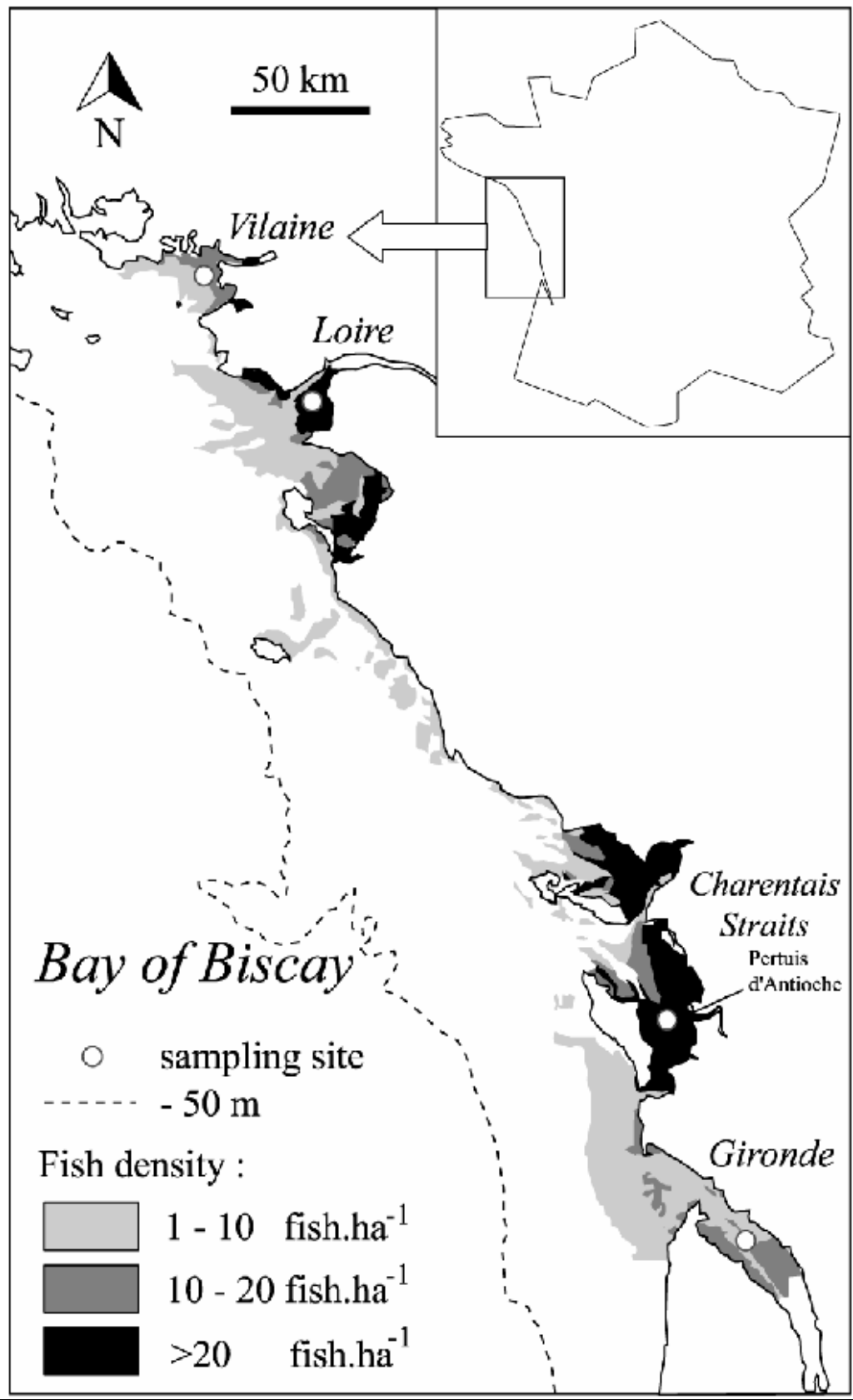

Fig. 1: Map of the study area. Grey levels indicate the estimated density of juveniles along the coast, delineating the areas used as nurseries along French coastline of Bay of Biscay (adapted from Le Pape et al. 2003a). 
Fig. 2
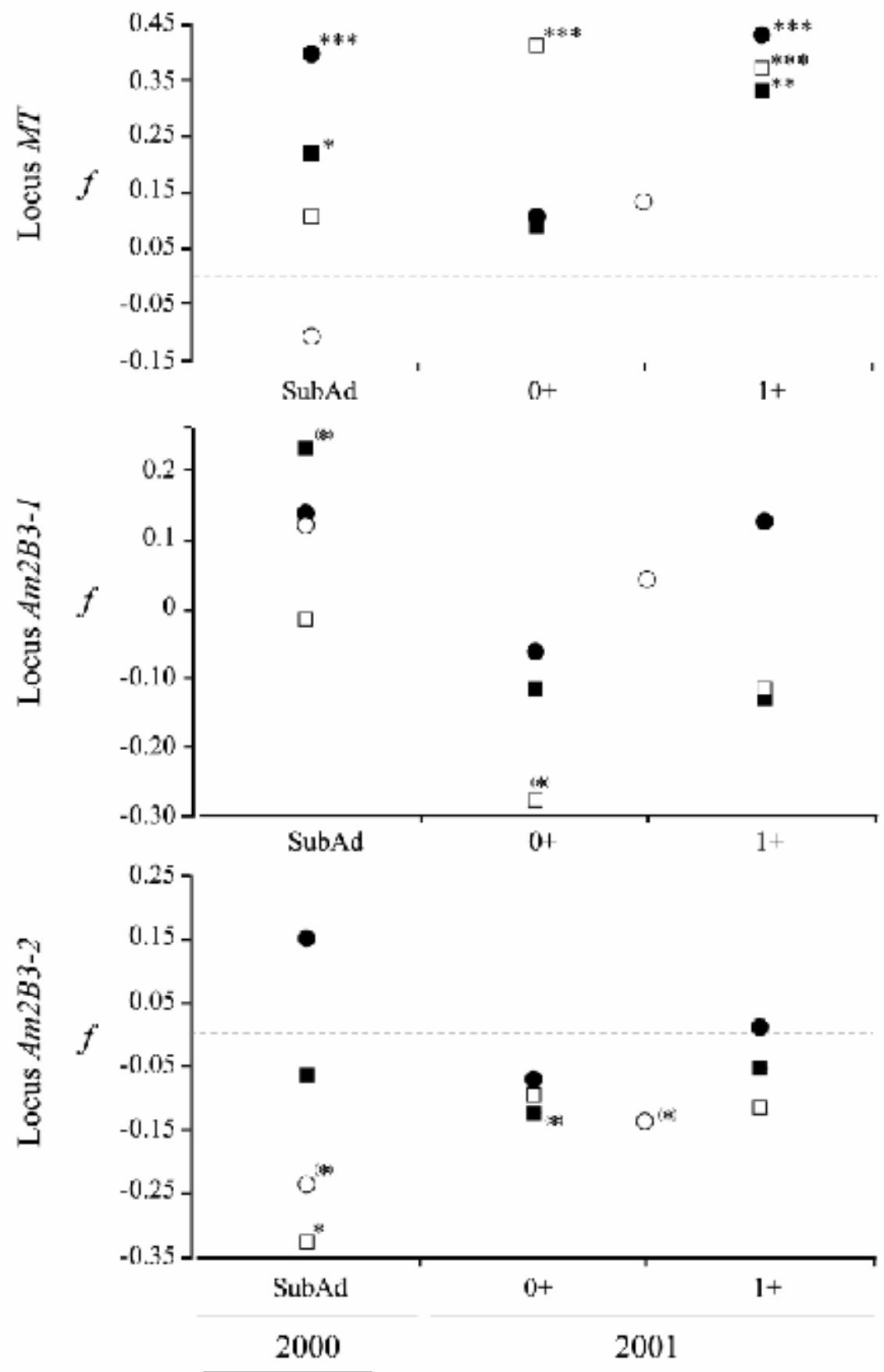

- Loire

- Vilaine

Age class

$\square$ Antioche

0 Gironde

Fig. 2: Observed values of multilocus $f$ for each locus and for each sample. Asterisks indicate significant

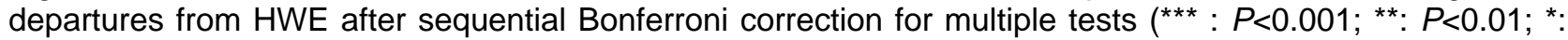
$P<0.05)$. Brackets indicated tests that were significant without considering correction for multiple test. The Gironde sample fished in 2001 being a mix of 0- and 1-group juveniles (Table 1), it is represented between the symbols of the other nurseries. 

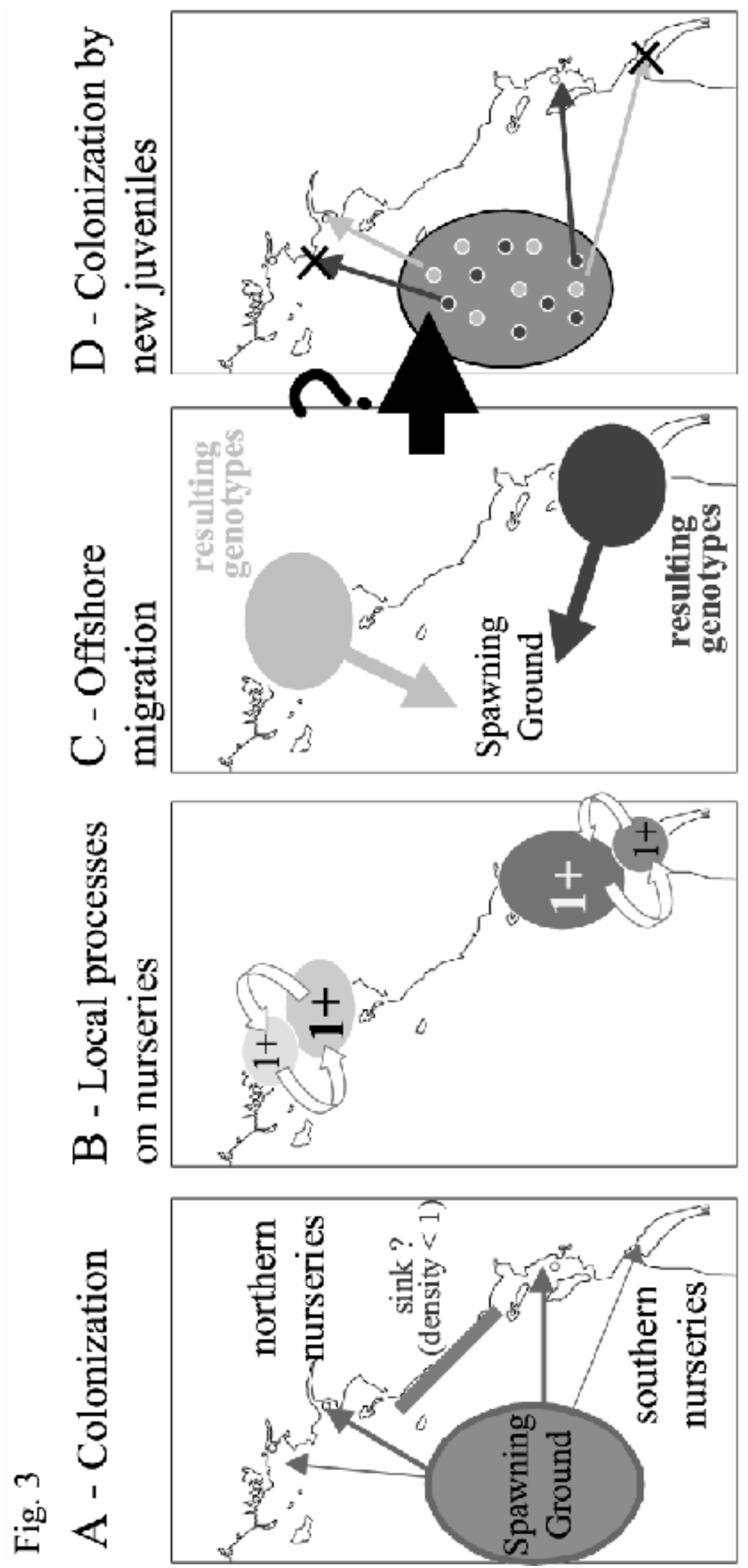

톨 
Fig. 3: A proposed model of sole population function in the Bay of Biscay based on genetic data and ecological knowledge. A: colonisation of main northern and southern Bay of Biscay nurseries by larvae originating from one single spawning ground, then from a single panmictic population. Larvae do not establish or poorly establish in some areas, due to poor habitat suitability for juvenile growth. Genetic drift may operate at this stage: individuals that establish at one nursery may reflect only one portion of the available genetic variability in some generations. B: Local process in each set of nurseries, including potential selection in the nurseries, possible local exchange among geographically clustered nurseries that must be facilitated by connection of river plumes or other physical processes, but absence of gene flow among the northern and southern nurseries. C: When leaving the nurseries, sub-adults possess distinct genetic backgrounds, as expressed by distinct grey levels, depending on their own history (A and B; then influenced by drift, gene flow, and/or selection). D: sub-adults derived from the different areas will mature, then mate randomly on spawning grounds. Sexual reproduction can rupture pre-existing genetic adaptation if individuals from different nurseries mate randomly. Conversely, sexual reproduction among individuals from the same nursery may favor locally adapted genetic associations, but random colonisation of nurseries by larvae of the next generation may take 'pre-adapted' individuals to the wrong local environment. Such individuals are then locally maladapted, have lower fitness and die (cross). 